Review of Quantitative Finance and Accounting, 1 (1991): 5-26

(C) 1991 Kluwer Academic Publishers, Boston. Manufactured in The Netherlands.

\title{
The Attributes, Behavior, and Performance of U.S. Mutual Funds
}

\author{
GREGORY CONNOR \\ University College, Dublin and University of California, Berkeley \\ ROBERT A. KORAJCZYK \\ University of Chicago and Northwestern University
}

\begin{abstract}
This article examines the risk and return characteristics of U.S. mutual funds. We employ an equilibrium version of the Arbitrage Pricing Theory (APT) and a principal-components-based statistical technique to identify performance benchmarks. We also consider the Capital Asset Pricing Model (CAPM) as an alternative. We implement a procedure for overcoming the rotational indeterminacy of factor models. This procedure is a hybrid of statistical factor estimation and prespecification of factors. We estimate measures of timing ability for the CAPM and extend it to the APT. We find that this timing test is misspecified due to noninformation-based changes in mutual fund betas. We develop a modification of the timing measure that, under certain conditions, distinguishes true timing ability from noninformation-based beta changes.
\end{abstract}

Key words: U.S. mutual funds, Arbitrage Pricing Theory, Capital Asset Pricing Model, rotational indeterminacy

\section{Introduction}

This article examines the risk and return characteristics of a sample of 130 U.S. mutual funds using 15 years of monthly return data. We use an equilibrium version of the Arbitrage Pricing Theory (APT) and a principal-components-based statistical methodology to develop our performance benchmarks. We also consider the Capital Asset Pricing Model (CAPM) as an alternative model.

In section 2 , we develop and apply an instrumental variables procedure to transform the factor betas of the APT into "economically meaningful" categories of risk in capital markets (such as inflation risk, term structure risk, and industrial output risk). In section 3, we estimate betas and selectivity-based performance measures for both the CAPM and APT. We find that selectivity-based performance measurement with the CAPM is compromised by the size effect in asset returns. Our APT also shows a smaller, but still significant, sizerelated bias.

In section 4 we present estimates of timing performance for the mutual funds. We use the approach developed by Henriksson and Merton (1981) and estimated by Henriksson (1984). We reestimate their model with our larger data set and some new techniques. We confirm and, in fact, strengthen Henriksson's key findings. We also apply the methodology to APT and find results very similar to those for the CAPM. 
Dynamic trading strategies and/or nonlinearities in the return-generating process can invalidate the measures of timing and selectivity proposed by Henriksson and Merton (1981). We describe an aggregate measure of total performance (timing plus selectivity) that remains valid under certain types of dynamic trading strategies or return nonlinearities. With this new version of the Henriksson-Merton model, we examine the dynamic risk adjustments undertaken by mutual funds, and evalute the effect of this dynamic behavior on the measurement of their timing performance. We uncover evidence that mutual fund betas covary with movements in the market portfolio return. However, we also find evidence that this correlation between mutual fund betas and market return is not caused by superior timing ability on the part of mutual fund managers. Rather, it arises from one of several possible sources of misspecification in the Henriksson-Merton model. Section 5 summarizes the findings of this article.

\section{Measuring the risk of mutual funds}

\subsection{Risk measurement with the CAPM and APT}

Under the CAPM, the compensated risk of an asset is measured by its market beta. Let $r_{i}$ denote the excess return (the return above the riskless return) on an asset or portfolio of assets. The CAPM assumes that the returns on assets have a multivariate normal distribution and that investors have one-period investment horizons. It is shown under these assumptions that all investors will hold combinations of the market portfolio of risky assets and the riskfree asset. Given joint normality of returns, one can always decompose asset excess returns into a constant, a market-related component, and a conditionally mean-zero residual term:

$$
\begin{aligned}
& r_{i}=\alpha_{i}+\beta_{i} r_{\mathrm{M}}+\epsilon_{i}, \\
& E\left[\epsilon_{i} \mid r_{\mathrm{M}}\right]=0,
\end{aligned}
$$

where $r_{M}$ is the excess return to the market portfolio and $\beta_{i}=\operatorname{cov}\left(r_{i}, r_{M}\right) / \operatorname{var}\left(r_{M}\right)$. In competitive equilibrium, the CAPM pricing relationship will hold and $\alpha_{i}=0$ for all $i=1$, $\ldots, n$. The CAPM also implies that an investor need only consider the beta of an asset or collection of assets to gauge its marginal impact on the risk of his optimal portfolio.

The APT begins with an assumption that the unexpected return of each asset is a linear combination of a set of $k$ factor shocks plus an asset-specific shock (see Ross, 1976):

$$
\begin{aligned}
& r_{i}=E\left[r_{i}\right]+B_{i 1} f_{1}^{*}+\ldots+B_{i k} f_{k}^{*}+\epsilon_{i}, \quad i=1, \ldots, n \\
& E\left[\epsilon_{i} \mid f^{*}\right]=0 .
\end{aligned}
$$

Let $\mathbf{f}^{\prime}=\left(f_{1}, \ldots, f_{k}\right)$ denote the excess returns to a set of $k$ portfolios with unit correlation to the factors $f_{1}^{*}, \ldots, f_{k}^{*}{ }^{1}$ Given equation (3), there exist factor betas $\beta_{i}=\left(\beta_{i 1}, \ldots, \beta_{i k}\right)$, $i=1, \ldots, n$, such that 


$$
r_{i}=\alpha_{i}+\beta_{i 1} f_{1}+\ldots+\beta_{i k} f_{k}+\epsilon_{i}, \quad i=1, \ldots, n .
$$

The APT predicts $\alpha_{i}=0$ for all $i$ (see Connor, 1984). It also asserts that an uninformed investor can determine the marginal risk contribution of an asset from the $k$-vector of factor betas $\beta_{i}$.

\subsection{Identifying the market portfolio and APT factors}

The estimated betas from the CAPM are only reliable to the extent that the market index return used in equation (1) provides an accurate proxy for the true market portfolio return (see Roll, 1978; Shanken, 1987). We use a standard proxy for the market, the value-weighted portfolio of NYSE/AMEX stocks from the Center for Research in Security Prices (CRSP).

One of the problems in using the APT to measure risk lies in the rotational indeterminacy in the definition of the factor model (5). Let $L$ denote a $k \times k$ nonsingular matrix and define the new set of mean-zero random variates $\mathbf{g}^{*}=L \mathbf{f}^{*}$. Define the excess returns to a set of mimicking portfolios by $\mathbf{g}=L \mathbf{f}$. If we define $\gamma=\beta L^{-1}$, then we can rewrite equation (5) using $\mathbf{g}$ and $\boldsymbol{\gamma}$ in place of $\mathbf{f}$ and $\boldsymbol{\beta}$. This implies that our estimated betas are specific to the particular rotation we use in identifying the factors. Hence, the beta estimates have little, if any, economic meaning, since they depend on an arbitrary rotation. Also, beta estimates from different time periods will not be comparable, since the factors will have a different rotation.

Chen, Roll, and Ross (1986) develop a model that eliminates the rotational indeterminacy of the APT. They propose a set of economic variates whose unexpected shocks can be used in place of $\mathrm{f}^{*}$. This provides a specific rotation (the same across different time periods) and allows us to interpret the factor betas in terms of meaningful macroeconomic risks. Chen, Roll, and Ross (1986) implicitly assume that the macroeconomic shocks are measured without error. They use the technique due to Fama and MacBeth (1973) to compute the excess returns to mimicking portfolios for these economic shocks.

We will apply a new technique for deriving mimicking portfolios for a given set of economic shocks. An advantage of this procedure is that we can treat the economic shocks as measured with error rather than as observed exactly. Our findings are consistent with the existence of a large amount of measurement error in these series.

This technique can be viewed as an application of two-stage least squares. Let $\mathbf{m}^{*}$ denote a $k$-vector of the true economic shocks ${ }^{3}$ and $\mathbf{m}$ a set of observable estimates. We assume the following:

$$
\begin{aligned}
& \mathbf{m}=\mathbf{m}^{*}+\mathbf{u} \\
& \mathbf{u} \sim N(\mathbf{0}, \Delta) .
\end{aligned}
$$

The $k$-vector $\mathrm{m}^{*}$ represents the true economic shocks (for example, unexpected inflation, output shocks, etc.) that are observed by investors and that influence time $t$ asset prices. The vector $\mathbf{m}$ represents the measured economic shocks available to the econometrician 
(for example, government-supplied data on prices and output used by the econometrician to estimate inflation and output shocks). The vector $\mathbf{u}$ is the measurement error of the econometrician.

Let $\mathbf{f}$ denote the $k$-vector of excess returns to portfolios that mimic $\mathbf{m}^{*}$ exactly:

$$
\mathbf{f}=\mathbf{m}^{*}+E[\mathbf{f}]
$$

That is, the mimicking-portfolio excess returns match m* exactly, except that their returns include risk premiums, captured by $E[\mathbf{f}]$.

Let $M, F, U$, and $M^{*}$ denote the $k \times T$ matrices of sample realizations (over $T$ periods) of $\mathbf{m}, \mathbf{f}, \mathbf{u}$, and $\mathrm{m}^{*}$. Let $\iota^{T}$ denote a $T$-vector of ones. Combining equations (6) and $(7)$ for the sample counterparts gives

$$
M=M^{*}+U=-E[\mathbf{f}]_{\iota}^{T}+F+U .
$$

In Connor and Korajczyk (1986), we describe a procedure for identifying the sample realizations of the statistical factors using a large cross section of security returns. In the limit, as the cross-sectional sample size, $n$, approaches infinity, this procedure gives a $k \times I$ matrix $G$ that equals $F$, subject to a rotational indeterminacy. That is,

$$
G=L F
$$

for some nonsingular $k \times k$ matrix $L$. Note that we can observe $G$ and $M$ and want to observe $F$. No matter how large the sample size, the factor estimates are subject to a rotational indeterminacy captured by the arbitrary nonsingular matrix $L$. This indeterminacy is shared by other factor-analytic estimation procedures such as those of Chen (1983) and Lehmann and Modest (1988).

Our procedure combines the information in $G$ and $M$ to estimate $F$ by inverting the rotation $L$. In the first stage, we regress each economic variable on $k$ statistical factors, $G$, with all variables demeaned before the regression (let $\sim$ denote a demeaned variable). This gives a $k \times k$ matrix of estimated coefficients $\hat{L}^{-1}$ for the economic variates:

$$
\hat{L}^{-1}=\tilde{M} \tilde{G}^{\prime}\left(\tilde{G} \tilde{G}^{\prime}\right)^{-1}
$$

In the second stage, we multiply these estimated coefficients by the statistical factor to get the explained economic variables, which we call the rotated factors. These are just a particular rotation of the statistical factors:

$$
\hat{F}=\hat{L}^{-1} G=F+U F^{\prime} L^{\prime}\left(L F F^{\prime} L^{\prime}\right)^{-1} L F .
$$

Note that $\hat{F}$ approaches $F$ as $T$ approaches infinity. Given a time series of portfolio excess returns $\mathbf{R}$, we use the rotated factors $\hat{F}$ to estimate alphas and betas by ordinary least squares applied to equation (5). The distributions of the resulting alpha and beta estimates are described in the appendix. 
The procedure is similar to conventional two-stage least squares except for its use of demeaned statistical factors in the first step (10) and the factors with their means in the second step (11). This is done so that the risk premiums of the factors, which appear in $F$ but not $M$, will be preserved in the rotated factors.

Note that our procedure constructs portfolios of the statistical factors that have maximum correlation with the macroeconomic variables. The procedure is similar to the Maximum Correlation Portfolio (MCP) procedure that Breeden, Gibbons, and Litzenberger (1989) develop for estimation and testing of the consumption CAPM. They define the MCP as the portfolio of assets that has maximum correlation with the growth rate of consumption.

\subsection{Choice of economic shocks}

We follow Chen, Roll, and Ross (1986) in our choice of economic shocks with some modifications. We choose four variates as the pervasive shocks: the shock to the term structure, the shock to the junk-bond premium, the shock to unemployment, and the shock to inflation.

We measure the shock to the term structure as the difference between the monthly return on long-term government bonds and monthly U.S. Treasury bills. We measure the shock to the junk-bond premium as the monthly return to a portfolio of low-grade corporate bonds minus the monthly return to high-grade corporate bonds. We estimate an autoregressive moving average model for inflation and use the innovations from this model as inflation shocks. Chen, Roll, and Ross (1986) use the one-month-ahead percentage change in the industrial production index as an output shock. In place of this variable we develop an autoregressive model for unemployment and use the one-month-ahead innovation from the model as an "output" shock. The fitted time series models for inflation and unemployment are reported in table 1 , while the correlations across macroeconomic series are reported in table 2.

Table 1. Fitted time series models inflation $\left(\mathrm{IF}_{t}\right)$ and changes in unemployment $\left(\Delta \mathrm{UN} \mathrm{N}_{t}\right)$. Monthly data from January 1968 to December 1982. 180 observations.

\begin{tabular}{|c|c|c|c|c|c|c|c|}
\hline & Constant & $\mathrm{IF}_{t-1}$ & $\mathrm{IF}_{t-2}$ & & $\bar{R}^{2}$ & DW & SEE \\
\hline \multirow[t]{2}{*}{$\mathrm{IF}_{t}$} & $\begin{array}{c}.138 \\
(3.28)\end{array}$ & $\begin{array}{r}.437 \\
(6.07)\end{array}$ & $\begin{array}{r}.324 \\
(4.46)\end{array}$ & & .443 & 2.01 & .245 \\
\hline & Constant & $\Delta \mathrm{UN}_{t-1}$ & $\Delta \mathrm{UN}_{t-2}$ & $\Delta \mathrm{UN}_{t-12}$ & $\bar{R}^{2}$ & DW & SEE \\
\hline$\Delta \mathrm{UN}_{t}$ & $\begin{array}{c}.406 \times 10^{-2} \\
(1.71)\end{array}$ & $\begin{array}{r}.205 \\
(2.78)\end{array}$ & $\begin{array}{r}.177 \\
(2.41)\end{array}$ & $\begin{array}{r}-.111 \\
(-1.57)\end{array}$ & .088 & 2.00 & $.309 \times 10^{-1}$ \\
\hline
\end{tabular}

This table shows the two autoregressive models used to find the unexpected components of inflation and unemployment. IF denotes the monthly percentage increase in the consumer price index; $\Delta U N$ is the change in the civilian unemployment rate. In all the tables, the $t$-statistics of the coefficients are in parentheses. The adjusted coefficient of determination $\left(\bar{R}^{2}\right)$, Durbin-Watson statistic (DW), and standard error of estimate (SEE) are also given. 
Table 2. Correlation matrix of the four macroeconomic shocks and the excess return on two market portfolio indices. Monthly data from January 1968 to December 1982 . 180 observations.

\begin{tabular}{|c|c|c|c|c|c|c|}
\hline & UIF & UPR & UTS & U $\Delta \mathbf{U N}$ & EWV & EEW \\
\hline UIF & 1.00 & & & & & \\
\hline UPR & .007 & 1.00 & & & & \\
\hline UTS & -.167 & -.620 & 1.00 & & & \\
\hline $\mathrm{U} \Delta \mathrm{UN}$ & .046 & -.062 & .008 & 1.00 & & \\
\hline EVW & -.240 & .049 & .350 & -.193 & 1.00 & \\
\hline EEW & -.245 & .074 & .311 & .242 & 9.13 & 1.00 \\
\hline
\end{tabular}

The four shocks are unexpected inflation (UIF), unexpected change in unemployment (UDUN), unexpected change in the bond risk premium (UPR), and the unexpected change in the term-structure premium (UTS). See the text for further description of these variables. EVW and EEW are the returns to the value-weighted and equally weighted CRSP indices, in excess of the one-month Treasury bill return.

\subsection{Rotation of the statistical factors}

In the empirical work we use a five-factor version of the APT. Each macroeconomic shock is regressed against five statistical factors. The predicted series from this regression serves as the new factor (see equation (9) above). We call this constructed variable a rotated factor, it is a linear combination of the statistical factors rotated so as to mimic the movements in a macroeconomic shock.

We only used four macroeconomic shocks in the analysis. For the final rotated factor, we rely on the assumption of the equilibrium version of the APT that the market portfolio is a linear combination of the factors. Our fifth and final rotated factor is a market residual factor-that is, the part of the value-weighted market index excess return that is not explained by the other four rotated factors. We regressed the value-weighted index on the first four rotated factors and used the residual from this regression as the fifth factor. This approach can be motivated by an equilibrium version of the APT (Connor, 1984) or by the existence of asymmetric information (Ketterer, 1987) and is discussed in McElroy and Burmeister (1988) and Wei (1988).

Table 3 describes the regressions of the macroeconomic shocks on the statistical factors. We use the statistical factors estimated by Connor and Uhlaner (1987). The factors are estimated over the 15-year period 1968-1982 using all NYSE traded firms that have complete data for the period. The low $\bar{R}^{2}$ values imply that most of the variation in the macroeconomic series is measurement error with respect to explaining stock market returns. Restated in terms of equation (6), this means that the variance of $\mathbf{u}$ is large relative to the variance of $\mathbf{m}^{*}$. As discussed above and in the appendix, the predicted series from these regressions form the rotated factors that we apply in the next section. The correlations of the rotated macrofactors appear in table 4. By construction, the market residual factor has a zero correlation with each of the other rotated factors.

\section{Fund attributes and selectivity-based performance measurement}

In Connor and Korajczyk (1986), we describe a competitive equilibrium model in which a small number of mutual fund managers possess superior information about the returns on specific securities, i.e., superior selection ability. Following Jensen (1968), we suggest 


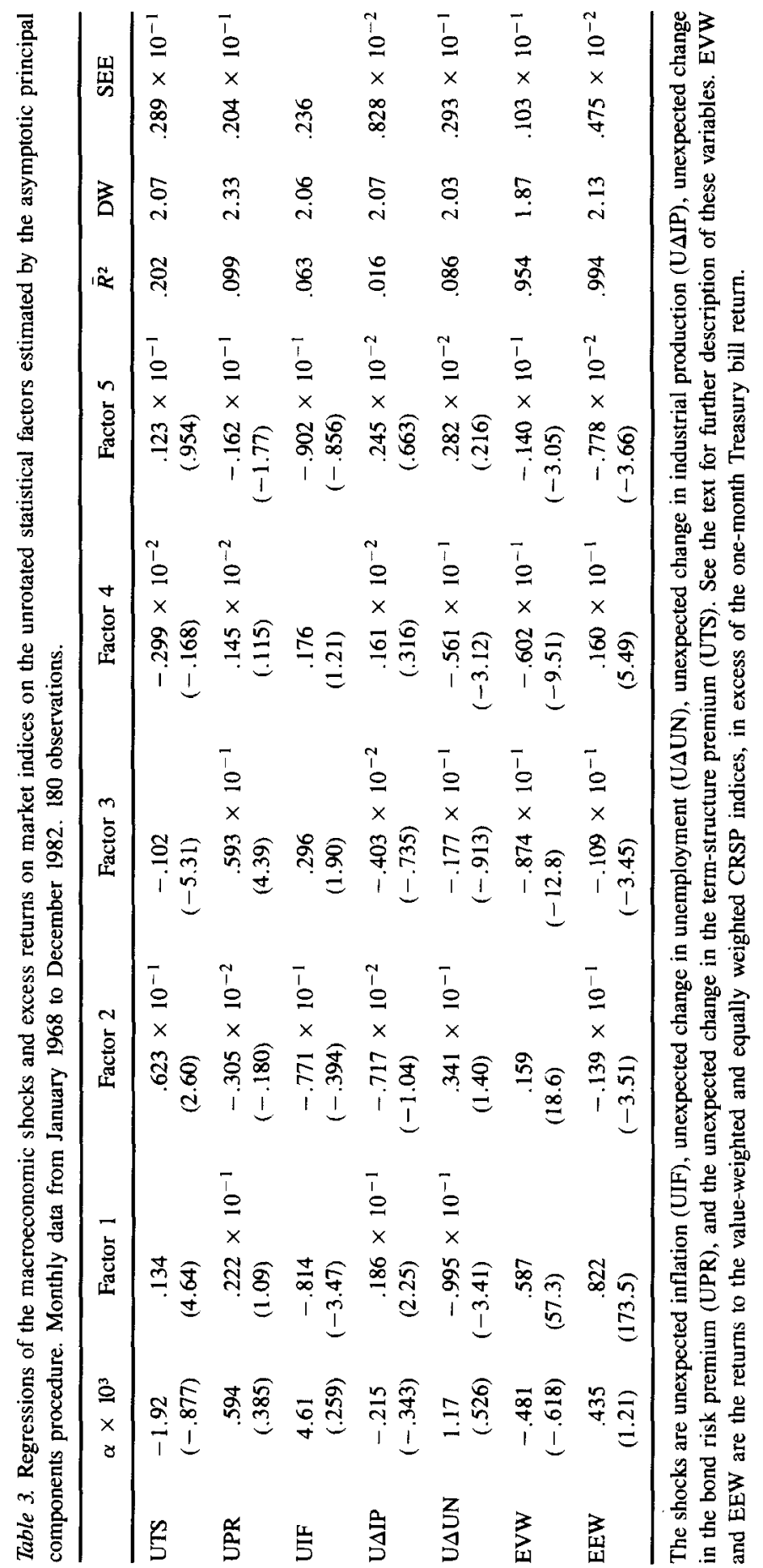


Table 4. Correlations matrix of the rotated macrofactors and excess returns on market indices. Monthly data from January 1968 to December 1982 . 180 observations.

\begin{tabular}{|c|c|c|c|c|c|c|c|}
\hline & UIFF & UPRF & UTSF & $\mathrm{U} \Delta \mathrm{UNF}$ & MKTRES & EVW & EEW \\
\hline UIFF & 1.00 & & & & & & \\
\hline UPRF & -.256 & 1.00 & & & & & \\
\hline UTSF & .847 & -.506 & 1.00 & & & & \\
\hline UAUNF & -.381 & -.238 & -.371 & 1.00 & & & \\
\hline MKTRES & 0 & 0 & 0 & 0 & 1.00 & & \\
\hline EVW & .852 & .129 & .752 & -.747 & .215 & 1.00 & \\
\hline EEW & .832 & .213 & 649 & -.747 & .013 & .913 & 1.00 \\
\hline
\end{tabular}

The macrofactors are UIFF (unexpected inflation factor), UPRF (unexpected change in the bond risk-premium factor), UTSF (unexpected change in the term-structure factor), UAUNF (unexpected change in unemployment factor), and MKTRES (market residual factor). See the text for a further description of the macrofactors.

an interpretation of equation (5) that can be used to detect the presence of superior selectivity. Let $r$ denote the excess return to the mutual fund under consideration. We show that in a competitive equilibrium model with a small set of informed investors, one can write the return on a managed portfolio as

$$
r=\alpha+\beta \mathbf{f}+\epsilon
$$

and that $\alpha>0$ implies that the manager has superior information. Let $\hat{\alpha}$ denote the estimates from applying ordinary least squares to equation (5). We show that

$$
\operatorname{dlim}_{T \rightarrow \infty} \operatorname{plim}_{n \rightarrow \infty} \hat{\alpha} \sim N\left(\alpha, \sigma_{\alpha}\right)
$$

The use of our rotated factors provides not only estimates of performance, $\hat{\alpha}$, but also estimates of the risk attributes of the funds. The betas of the fund relative to our rotated factors represent the risk of the fund relative to equity portfolios that are maximally correlated with the macroeconomic series. Thus, an investor can ascertain a fund's sensitivity to particular shocks. For example, a pension fund concerned about exposure to interest rate movements may have a particular interest in the fund's beta relative to term-structure shocks.

Our data set consists of the monthly returns (including dividends and net of transactions costs) for 130 mutual funds from 1968 to 1982 . We also have the Weisenberger Investment Survey classifications of the funds according to their investment objective: income, stabilitygrowth-income, growth-income, growth, or maximum capital gain. This classification is based on a reading of the fund's prospectus and is released prior to the beginning of the time series sample of returns. Hence, we can use it as an independent source of information on the risk levels of the funds.

First, we perform the regressions on the individual funds (tables 5 and 6). Each regression is over the available sample for that fund (some funds did not exist or their returns were not recorded for the full 15 years). Next, we take cross-sectional averages of the estimated coefficients, estimated $t$-statistics, standard errors of regression, and $\bar{R}^{2}$. Since the unexplained returns of the funds are less than perfectly correlated, the cross-sectional average $t$-statistics understate the true multivariate significance levels. Using standard significance levels is a conservative procedure. 
Table 5. Average CAPM alpha and beta estimates for individual mutual funds. Monthly data from January 1968 to December 1982 . 180 observations.

\begin{tabular}{|c|c|c|c|c|}
\hline Fund type & $\alpha \times 10^{3}$ & $\beta$-EVW & $\bar{R}^{z}$ & SEE $\times 10$ \\
\hline Income & $\begin{array}{c}.190 \\
(.343)\end{array}$ & $\begin{array}{l}.693 \\
(10.2)\end{array}$ & .710 & .198 \\
\hline Stability-growth-income & $\begin{array}{c}-.317 \\
(-.536)\end{array}$ & $\begin{array}{l}.747 \\
(10.3)\end{array}$ & .851 & .146 \\
\hline Growth-income & $\begin{array}{c}.072 \\
(.173)\end{array}$ & $\begin{array}{l}.905 \\
(17.6)\end{array}$ & .889 & .149 \\
\hline Growth & $\begin{array}{c}.060 \\
(.173)\end{array}$ & $\begin{array}{r}1.03 \\
(24.2)\end{array}$ & .808 & .232 \\
\hline Maximum capital gain & $\begin{array}{r}-.758 \\
(-1.33)\end{array}$ & $\begin{array}{r}1.16 \\
(16.6)\end{array}$ & .769 & .305 \\
\hline
\end{tabular}

The mutual funds are sorted into five risk classes: I (income), SGI (stability-growth-income), GI (growth-income), $\mathrm{G}$ (growth), and MCG (maximum capital gain). All of the estimates are the averages (across all of the mutual funds within each risk class) of the corresponding estimates for the individual time series regressions. The numbers reported in parentheses are the average $t$-statistics. The average $t$-statistics give a lower bound to the true multivariate significance of the cross section of estimated coefficients. $\beta$-EVW denotes the beta with respect to the valueweighted CRSP portfolio.

Table 6. Average APT alpha and beta estimates for individual mutual funds. Monthly data from January 1968 to December 1982. 180 observations.

\begin{tabular}{lcccccccc}
\hline \multicolumn{1}{c}{ Fund type } & $\alpha \times 10^{3}$ & UTSF & UPRF & UIFF & UAUNF & MKTRES & $\bar{R}^{2}$ & SEE $\times 10$ \\
\hline Income & -.651 & .508 & .504 & .864 & -2.39 & .174 & .773 & .169 \\
& $(-.369)$ & $(5.77)$ & $(7.84)$ & $(6.73)$ & $(-3.58)$ & $(1.30)$ & & \\
Stability-growth- & -.999 & .696 & .642 & .813 & -.167 & .361 & .868 & .135 \\
income & $(-.913)$ & $(9.77)$ & $(12.0)$ & $(6.76)$ & $(-.013)$ & $(3.84)$ & & \\
Growth-income & -.134 & .919 & .921 & .928 & .991 & .677 & .904 & .138 \\
& $(-.186)$ & $(11.9)$ & $(16.3)$ & $(8.28)$ & $(1.22)$ & $(7.21)$ & & \\
Growth & -.194 & .907 & 1.04 & 1.25 & .833 & .648 & .832 & .215 \\
& $(-.211)$ & $(8.03)$ & $(13.3)$ & $(7.26)$ & $(1.05)$ & $(4.89)$ & & .275 \\
Maximum & -1.24 & .979 & 1.27 & 1.44 & -.204 & .444 & .807 & .275 \\
capital gain & $(-.767)$ & $(5.25)$ & $(10.4)$ & $(5.44)$ & $(-.203)$ & $(2.33)$ & & \\
\hline
\end{tabular}

The mutual funds are sorted into five risk classes: I (income), SGI (stability-growth-income), GI (growth-income), $\mathrm{G}$ (growth), and MCG (maximum capital gain). All of the estimates are the averages (across all of the mutual funds within each risk class) of the corresponding estimates for the individual time series regressions. The numbers reported in parentheses are the average $t$-statistics. Betas are relative to the rotated macrofactors UIFF (unexpected inflation factor), UPRF (unexpected change in the bond risk-premium factor), UTSF (unexpected change in the term-structure factor), USUNF (unexpected change in unemployment factor), and MKTRES (market residual factor).

The rotated factors are scaled so that the value-weighted index has a beta of one for each factor. This has no effect on the estimated performance or the statistical tests but makes the estimated betas easier to interpret. A mutual fund with an inflation beta greater (less) 
than one has more (less) inflation sensitivity than the market index. The estimates of beta provide an interesting picture of the attributes of the funds in terms of their exposure to the various sources of risk. The CAPM betas increase monotonically as we move along the risk spectrum from income funds to maximum capital gains funds. The APT betas show a somewhat different picture. The fund betas for term structure risk, default risk, and inflation risk increase almost monotonically along the risk spectrum, but unemployment risk and market residual risk increase and peak for growth/income funds and then decline.

As an alternative to the individual fund regressions, we construct equally weighted portfolios of all funds of each risk type that has recorded returns for the full 15-year period. We then perform the regressions on these portfolios of mutual funds. These results are presented in tables 7 and 8. The basic pattern of risk attributes is as in tables 5 and 6 , although the levels of significance are higher because of the more precise estimates.

In terms of performance, the value-weighted CAPM finds one significant (negative) abnormal return across fund portfolios (table 7). The APT shows significantly negative abnormal performance for two portfolios but with low coefficients (table 8). All the significant coefficients for the APT are within the range that might be explained by reasonable mutual fund transactions costs.

Our estimates of performance combine true performance, estimation error, and failure of the models to price assets appropriately. Therefore, it is important to investigate the performance of the CAPM and APT on passive portfolios to get some idea of the extent of their pricing errors. To do this, we also examine the "performance" of ten size-sorted portfolios using the techniques used above. We divided the NYSE monthly returns available from CRSP into ten equally weighted portfolios sorted by firm capitalization. Since these portfolios are informationally passive $\mathrm{e}^{4}$ and incur no transactions costs, they should not exhibit significant abnormal performance. We find that the well-known size bias of the CAPM appears. The APT also shows a size-induced bias that is smaller than the CAPM bias. The APT produces two individually significant coefficients for the size-decile portfolios,

Table 7. CAPM alpha and beta estimates for risk-class portfolios of mutual funds. Monthly data from January 1968 to December 1982. 180 observations.

\begin{tabular}{|c|c|c|c|c|c|}
\hline Fund type & $\alpha \times 10^{3}$ & $\beta$-EVW & $\bar{R}^{2}$ & DW & SEE $\times 10$ \\
\hline Income & $\begin{array}{c}-.128 \\
(-.162)\end{array}$ & $\begin{array}{l}.661 \\
(39.7)\end{array}$ & .899 & 1.55 & .106 \\
\hline Stability-growth-income & $\begin{array}{c}.061 \\
(.095)\end{array}$ & $\begin{array}{l}.780 \\
(57.7)\end{array}$ & .949 & 1.64 & .086 \\
\hline Growth-income & $\begin{array}{r}-.776 \\
(-2.13)\end{array}$ & $\begin{array}{c}.763 \\
(99.8)\end{array}$ & .982 & 1.77 & .049 \\
\hline Growth & $\begin{array}{c}1.23 \\
(1.39)\end{array}$ & $\begin{array}{r}1.23 \\
(65.9)\end{array}$ & .961 & 1.57 & .119 \\
\hline Maximum capital gain & $\begin{array}{c}.012 \\
(.009)\end{array}$ & $\begin{array}{r}1.08 \\
(40.7)\end{array}$ & .903 & 1.63 & .169 \\
\hline
\end{tabular}

The mutual funds are sorted into five risk classes: I (income), SGI (stability-growth-income), GI (growth-income), G (growth), and MCG (maximum capital gain). Equally weighted portfolios of mutual funds are formed based on the five mutual fund risk classes. $\beta$-EVW denotes the beta with respect to the value-weighted CRSP portfolio. 
Table 8. APT alpha and beta estimates for risk-class portfolios of mutual funds. Monthly data from January 1968 to December 1982. 180 observations.

\begin{tabular}{lccccccccc}
\hline \multicolumn{1}{c}{ Fund type } & $\alpha \times 10^{3}$ & UTSF & UPRF & UIFF & USUNF & MKTRES & $\bar{R}^{2}$ & DW & SEE $\times 10$ \\
\hline Income & -1.14 & .510 & .520 & .826 & -1.77 & .163 & .941 & 1.44 & .081 \\
& $(-1.88)$ & $(12.2)$ & $(17.5)$ & $(12.6)$ & $(-5.44)$ & $(2.75)$ & & & \\
Stability-growth- & -.665 & .676 & .664 & .941 & -.522 & .352 & .969 & 1.78 & .067 \\
income & $(-1.31)$ & $(19.4)$ & $(26.6)$ & $(17.2)$ & $(-1.92)$ & $(7.10)$ & & & \\
Growth-income & -.913 & .750 & .772 & .790 & .563 & .585 & .985 & 1.90 & .045 \\
& $(-2.67)$ & $(32.0)$ & $(46.2)$ & $(21.5)$ & $(3.08)$ & $(17.6)$ & & & \\
Growth & -1.01 & 1.10 & 1.25 & 1.49 & 1.24 & .812 & .967 & 1.64 & .108 \\
& $(-1.24)$ & $(19.7)$ & $(31.3)$ & $(17.0)$ & $(2.84)$ & $(10.2)$ & & & \\
Maximum & -.239 & 1.00 & 1.17 & 1.24 & .822 & .518 & .917 & 1.80 & .156 \\
capital gains & $(-.202)$ & $(12.4)$ & $(20.2)$ & $(9.79)$ & $(1.30)$ & $(4.51)$ & & & \\
\hline
\end{tabular}

The mutual funds are sorted into five risk classes: I (income), SGI (stability-growth-income), GI (growth-income), G (growth), and MCG (maximum capital gain). Equally weighted portfolios of mutual funds are formed based on the five mutual fund risk classes. Betas are relative to the rotated macrofactors UIFF (unexpected inflation factor), UPRF (unexpected change in the bond risk-premium factor), UTSF (unexpected change in the termstructure factor), U $\Delta \mathrm{UNF}$ (unexpected change in unemployment factor), and MKTRES (market residual factor).

and there is a tendency for the alpha estimate to decrease with size. The magnitude of the bias is larger for the CAPM, but the APT does not fully eliminate it. The full results are not reported here to conserve space, but are available in an earlier version of this article (Connor and Korajczyk, 1988b, table 5). The same findings, for a slightly different sample, are reported in Connor and Korajczyk (1988a).

\section{Henriksson-Merton tests and an alternative timing model}

The analysis of the last section treated superior performance due to asset-specific information, whereas in this section we consider factor or market information, known as timing ability. Merton (1981), Henriksson and Merton (1981), and Henriksson (1984) develop and apply an interesting econometric approach to measuring timing ability. In this section, we reestimate the Henriksson-Merton model with our data set, extend the tests to the multifactor case, and develop a new version of their model that allows for noninformation-based variation in the factor or market risk of the portfolio under consideration.

The Henriksson-Merton model that we use assumes that the portfolio manager receives a binary signal (high or low) each period that is correlated with the true outcome of the market return realization. He chooses one of two values for the portfolio beta (high or low) in response to the signal received. Henriksson and Merton (1981) prove that the following regression gives consistent estimates of timing ability:

$$
r=\alpha+\beta r_{M}+\gamma \operatorname{put}\left(r_{M}\right)+\epsilon,
$$

where

$$
\operatorname{put}(x)=\max (-x, 0)
$$


They show that $\gamma>0$ if and only if the investor possesses superior market timing ability and $\alpha>0$ if the manager has selection ability. The extension to a multifactor model is immediate:

$$
r=\alpha+\beta_{1} r_{f 1}+\ldots+\beta_{k} r_{f k}+\gamma_{1} \operatorname{put}\left(r_{f 1}\right)+\ldots+\gamma_{k} \operatorname{put}\left(r_{f k}\right)+\epsilon
$$

where $\gamma_{j}>0$ if and only if the manager has superior information about factor $j$. The $\alpha$ term is included to measure selection ability and, as in the last section, $\alpha>0$ implies superior selectivity. In the empirical work reported below, we simplified equation (13) to include only the put on the market portfolio (which is a linear combination of the factor portfolios).

Henriksson (1984) estimates equation (12) for a sample of 116 mutual funds (all of which are used in this study as well). He finds little evidence of superior timing ability, that is, significantly positive gammas. In fact, he notes that more of the funds have negative estimated gammas than positive ones. Also, he provides some evidence that the estimate of gamma is negatively correlated with the estimate of alpha across funds. He conjectures that this may be due to errors-in-variables. Chang and Lewellen (1984) also estimate the model and reach conclusions similar to those of Henriksson. ${ }^{5}$

Both Chang and Lewellen (1984) and Henriksson (1984) use individual mutual fund returns in their empirical tests. We reestimate the model using our risk-sorted portfolios of mutual funds. An advantage of this approach is lower residual variance in the regression and, hence, more precise estimates of the parameters. An obvious potential disadvantage is the masking of interesting cross-sectional differences in funds of the same type. Empirically, this data reduction technique significantly strengthens the findings of the two earlier studies concerning the prevalence of negative estimated gammas and the negative correlation between estimated gamma and alpha. The results that were only hinted at in the earlier two studies are now strongly confirmed. Two of the semipassive funds have significantly negative timing coefficients. The same two funds have significantly positive selectivity coefficients (see table 9). The $t$-statistics in tables 9-12 use the heteroskedasticity-consistent standard error procedure of White (1980) and Hsieh (1983).

One possibility is that a significant $\gamma$ coefficient in equation (12) reflects the multiple factors of the APT that are not adequately captured by the market index. In this case, we would expect the coefficient to disappear in equation (13). In fact, the coefficient $\gamma$ is little affected in moving from equation (12) to equation (13) (see table 9 versus 10).

If we accept the Henriksson-Merton model, the significantly negative timing coefficients in tables 9 and 10 are a paradox for the following reason. The Henriksson-Merton model distinguishes between significantly positive gamma (superior information rationally acted upon) and zero gamma (no superior information). In order to produce a negative gamma, an investor must possess superior information and employ it irrationally, i.e., raise market risk when he receives a signal that the market will fall and lower market risk when he receives a signal that the market will rise. We will call this behavior perverse timing ${ }^{6}$ At the same time that the fund manager is engaging in perverse timing, he has excellent selection ability - the funds have high positive alphas. It seems sensible to search for an alternative explanation for the results of tables 9 and 10 that goes outside the original HenrikssonMerton model. 
Table 9. CAPM-based Henriksson-Merton estimates for risk-class portfolios of mutual funds. Monthly data from January 1968 to December 1982. 180 observations.

\begin{tabular}{lcccccc}
\hline \multicolumn{1}{c}{ Fund type } & $\alpha \times 10^{3}$ & $\beta$-EVW & $\gamma$-PUT $\times 10$ & $\bar{R}^{2}$ & DW & SEE $\times 10$ \\
\hline Income & -.471 & .669 & .184 & .899 & 1.56 & .106 \\
Stability-growth-income & .175 & .777 & -.061 & .949 & 1.64 & .087 \\
Growth-income & $(.168)$ & $(31.2)$ & $(-.140)$ & & & .049 \\
& -.480 & .755 & -.159 & .982 & 1.75 & .343 \\
Growth & $(-.818)$ & $(53.7)$ & $(-.644)$ & & & .118 \\
& 3.42 & 1.17 & -1.18 & .961 & 1.53 & \\
Maximum capital gain & $(2.42)$ & $(34.5)$ & $(-1.97)$ & & & .167 \\
\end{tabular}

Regressions of the excess return of risk-sorted mutual fund portfolios on the excess return to the value-weighted CRSP portfolio, an intercept, and a European put option on the market index (PUT). See the text for a fuller description of the put option. $T$-statistics (in parentheses) are computed using the Hansen-White heteroskedasticityconsistent standard errors.

As Henriksson and Merton note, the informational advantage they model is equivalent to the ownership at no cost of a put option on the market portfolio. A negative gamma and an alpha equal to zero are correspondingly equivalent to shorting a market put option without receiving cash.

There are at least three ways besides market timing that a mutual fund portfolio could include put-option payoffs in its return. First, the fund could buy or sell traded puts on individual securities or on market indices. Second, it could follow a dynamic trading strategy that replicates a put. Third, the underlying return process driving assets could have betanonlinearities arising from leverage effects or from other sources that give rise to a putlike structure to returns. We will call these the marketed options (MO), dynamic trading (DT), and asset beta nonlinearities ( $\mathrm{ABN})$ models.

A cursory examination of mutual fund annual reports reveals that the MO model is not reasonable. Mutual funds have very limited holdings of put and call options; most of them hold none at all.

The DT model, hypothesizing that mutual funds engage in dynamic trading strategies that replicate a put option, cannot be readily dismissed. The original Henriksson-Merton model assumes that the trading decisions of investors are made only at the same intervals as the return observations used in the tests (in this article, monthly). If investors trade more frequently than we measure returns, then their dynamic decisions (without any superior information) can create false evidence of timing. With continuous trading, they can perfectly replicate a put, without any special information. This problem with discretely measured returns and continuously trading investors was analyzed by Pfleiderer and Bhattacharya (1983).

The ABN model is motivated by the putlike properties of debt and equity given a nonzero risk of corporate bankruptcy. Suppose that the return process (1) governs the market value of the firm as a whole and that the firm issues straight debt with a nonzero probability 


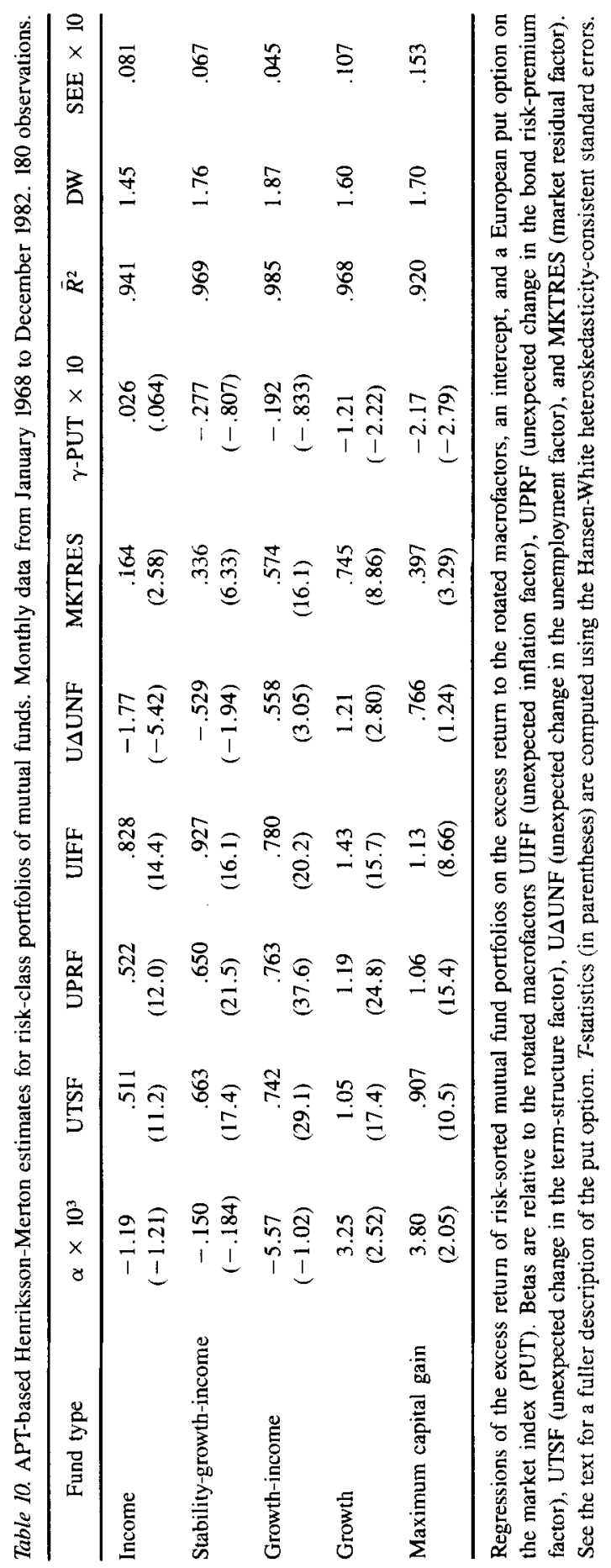


of default. Then the equity of the firm will have a return process that is the return process of the market value of the firm, plus a put option. The debt will have a riskless return stream, minus the return stream of a put option. If mutual funds purchase debt and equity of leveraged firms, then their return streams will reflect these implicit options. This explanation for Henriksson's findings of negative gammas was suggested in Jagannathan and Korajczyk (1986). Although it is motivated by the leverage analysis described above, it is not limited to this case. Asset beta nonlinearities could also arise from other sources, such as the nature of the production process over the business cycle (i.e., operating leverage).

We now have four models to explain the results of a Henriksson-Merton test: the original explanation of superior timing, purchase or sale of marketed options, dynamic trading strategies, and beta nonlinearities in asset returns. We reject the first of these because it cannot explain negative timing coefficients. We reject the second because our examination of mutual fund balance sheets reveals little activity in the options market.

The third and fourth explanations share a common feature. They both imply that the mutual funds are fully compensated for their position in the put option. The HenrikssonMerton model views the funds as owning a free put option. The DT and ABN models view the funds as buying (or shortselling) costly puts. In the absence of selection ability, the cash flow from the costly put makes these models distinct from the Henriksson-Merton model, since the cost of the options will be reflected in the mean returns through the intercept. The Henriksson-Merton model can be distinguished from the DT and ABN models via the following regression:

$$
r=\alpha+\beta r_{M}+\gamma \operatorname{put}\left(r_{M}\right)+\epsilon
$$

If the manager has no timing or selection ability, the Henriksson-Merton model predicts $\alpha=0$, whereas the DT and ABN models predict

$$
\alpha=-\left(1+r_{0}\right) \gamma P_{0}
$$

where $P_{0}$ is the time-zero market value of the put and $r_{0}$ is the riskless return (see Jagannathan and Korajczyk, 1986). This shows the negative relation between alpha and gamma.

The negative correlation between gamma and alpha evident in tables 9 and 10 is consistent with the DT and ABN models (see equation (15)). It is only consistent with the Henriksson-Merton model in the presence of perverse timing ability and superior selectivity ability across the whole group of $\mathrm{G}$ funds and of MCG funds.

A related test of the DT and ABN models can be formulated by transformation of equation (14) using equation (15). We construct a new variable that we call a net put. This is the payoff to a market put minus the Treasury bill return necessary to pay the market price of the put.

$$
\text { nput }=\text { put }-\left(1+r_{0}\right) P_{0} \text {. }
$$

This new instrument is widely known by another name-it is simply a portfolio insurance contract. An investor who holds this instrument and the market portfolio is guaranteed the risk-free return minus the future value (at the riskless rate) of the put price. 
In the absence of timing ability, the following equation can be used to test the models:

$$
r=\alpha^{*}+\beta\left(r_{M}\right)+\gamma \text { nput }+\epsilon
$$

Given zero selection and timing ability, the Henriksson-Merton model predicts $\alpha^{*}=$ $\gamma\left(1+r_{0}\right) P_{0}$, whereas the DT and ABN models predict $\alpha^{*}=0$.

Note that equation (16) is consistent with all three suggested models (Henriksson-Merton, $\mathrm{DT}$, and $\mathrm{ABN}$ ). Under the null hypothesis of no selection and timing ability, even when the manager is trading option like securities, $\alpha^{*}$ should be zero. If the manager has true selection or timing ability (of the type described in Henriksson and Merton (1984)), then $\alpha^{*}$ should be greater than zero.

The new specification (16) has the disadvantage relative to equation (14) that only the sum of timing value and selectivity value can be measured. The original Henriksson-Merton model as reflected in equation (14) allows these two components to be separated when the conditions of the Henriksson-Merton model hold. The new model has the advantage over Henriksson-Merton that it still gives a consistent measure of performance when mutual funds buy or sell costly puts. Another limitation is that it only allows for one-month-ahead European options, whereas the return of the fund could correspond to an infinite variety of optionlike patterns. We hope that this simplest option pattern captures the essential part of the nonlinearity in returns. ${ }^{\text {? }}$

Table 11 provides evidence on the Henriksson-Merton model versus our model. We use the Black-Scholes formula to price the put option. Note that the put option is a European put option against a non-dividend-paying market index and so can be evaluted in closed form, given the risk-free return and the variance of the market index. We use the Treasury bill return as the risk-free return, and we estimate the variance of the market index by the sample variance of the excess return to the market index over the same 15-year period.

Table 11. CAPM-modified Henriksson-Merton estimates for risk-class portfolios of mutual funds. Monthly data from January 1968 to December 1982, 180 observations.

\begin{tabular}{lcccccc}
\hline \multicolumn{1}{c}{ Fund type } & $\alpha^{*} \times 10^{3}$ & $\beta$-EVW & $\gamma$-NPUT & $\bar{R}^{2}$ & DW & SEE $\times 10$ \\
\hline Income & -.121 & .669 & .019 & .899 & 1.56 & .106 \\
& $(-.152)$ & $(21.8)$ & $(.343)$ & & & \\
Stability-growth-income & .058 & .777 & -.006 & .949 & 1.64 & .087 \\
Growth-income & $(.091)$ & $(31.2)$ & $(-.136)$ & & & .049 \\
Growth & -.782 & .755 & -.159 & .982 & 1.75 & .118 \\
& $(-2.15)$ & $(53.7)$ & $(-.647)$ & & & .53 \\
Maximum capital gain & 1.18 & 1.17 & -.117 & .961 & 1.53 & .167 \\
& $(1.35)$ & $(34.5)$ & $(-1.97)$ & & & \\
\end{tabular}

Regressions of the excess return of risk-sorted mutual fund portfolios on the excess return to the value-weighted CRSP portfolio, an intercept, and the excess return to a put option on the market index (NPUT). See the text for a fuller description of the NPUT. T-statistics (in parentheses) are computed using the Hansen-White heteroskedasticity-consistent standard errors. 
Table 11 indicates that the DT or ABN models are superior to the Henriksson-Merton model. The abnormal performance of both the growth and maximum capital gains portfolios are eliminated by allowing for costly market put options in their returns. The findings in tables 9, 10, and 11 seem to indicate that the Henriksson-Merton model mostly captures noninformation-based dynamic variation in the betas of mutual funds rather than any timing ability (perverse or otherwise) by mutual fund portfolio managers.

The DT and ABN models are also distinct from one another. If the put options are impounded in the securities purchased by the mutual funds (ABN), then the timing tests (16) run against passive portfolio indices will produce nonzero gammas. If static portfolios do not exhibit nonzero gamma, then the mutual funds must be creating the put options through their dynamic trading behavior (DT).

We attempt to distinguish between the DT and $\mathrm{ABN}$ models by estimating equation (16) on passive indices-the size-decile portfolios described earlier. The ABN model posits that the put options are impounded in the securities purchased by the mutual funds. If this is the case, then these same nonlinearities can be found in unchanging portfolios of assets such as the size-decile portfolios. The DT model assumes that the mutual funds create the nonlinearities through their dynamic trading. In this case, the nonlinearities will not appear in the size-decile portfolios.

Table 12 shows that the results of these tests are mixed. While there is only one sizedecile with a significant gamma, there is a definite pattern in the sign of gamma. This single test is not conclusive evidence for the DT model over the ABN model. It may be that the growth and maximum capital-gains mutual funds concentrate in particular industries or types of firms that have nonlinearities in their betas, and that these are not selected out in the size portfolios. Table 12 only shows that the asset beta nonlinearities, if they exist, are not size-based. Jagannathan and Korajczyk (1986) use value-weighted and equalweighted market portfolios as passive portfolios over the 1926-1981 period. Their evidence is consistent with the ABN model.

\section{Summary}

This article uses a sample of 130 mutual funds over a 15 -year period to analyze portfolio performance measurement with the CAPM and APT. We find that performance measurement with either model is compromised by the size effect in asset returns. The size effect is larger in the CAPM, but is not fully eliminated in the APT.

We develop an instrumental variables technique to transform the statistical factors of the APT into meaningful categories of economic risk. The technique uses economic variables as a basis for rotating statistically identified factors.

We reestimate the timing tests of Henriksson and Merton and extend them to the APT. We find strong empirical evidence that these tests must be adjusted for noninformationbased changes in mutual fund betas. We develop and implement an adjusted version of the Henriksson-Merton test that allows for these changes and simultaneously measures the sum of timing and selectivity performance of a fund. 
Table 12. CAPM modified Henriksson-Merton estimates for size-decile portfolios and market indices. Monthly data from January 1968 to December 1982. 180 observations.

\begin{tabular}{|c|c|c|c|c|c|c|}
\hline Decile & $\alpha^{*} \times 10^{3}$ & $\beta$-EVW & $\gamma$-NPUT & $\bar{R}^{2}$ & DW & SEE $\times 10$ \\
\hline 1 (Smallest) & $\begin{array}{c}7.43 \\
(2.07)\end{array}$ & $\begin{array}{c}1.16 \\
(8.41)\end{array}$ & $\begin{array}{l}-.111 \\
(-.457)\end{array}$ & .596 & 2.13 & .481 \\
\hline 2 & $\begin{array}{c}5.52 \\
(2.05)\end{array}$ & $\begin{array}{r}1.13 \\
(10.9)\end{array}$ & $\begin{array}{c}-.088 \\
(-.482)\end{array}$ & .708 & 2.11 & .361 \\
\hline 3 & $\begin{array}{c}5.62 \\
(2.57)\end{array}$ & $\begin{array}{r}1.13 \\
(13.4)\end{array}$ & $\begin{array}{c}-.572 \\
(-.387)\end{array}$ & .782 & 2.08 & .293 \\
\hline 4 & $\begin{array}{l}4.96 \\
(2.68)\end{array}$ & $\begin{array}{r}1.02 \\
(14.3)\end{array}$ & $\begin{array}{l}-.108 \\
(-.862)\end{array}$ & .812 & 1.87 & .248 \\
\hline 5 & $\begin{array}{c}2.49 \\
(1.43)\end{array}$ & $\begin{array}{r}1.08 \\
(16.2)\end{array}$ & $\begin{array}{l}-.556 \\
(-.004)\end{array}$ & .833 & 2.04 & .233 \\
\hline 6 & $\begin{array}{c}1.96 \\
(1.21)\end{array}$ & $\begin{array}{r}1.13 \\
(17.9)\end{array}$ & $\begin{array}{c}-.016 \\
(-.146)\end{array}$ & .861 & 2.04 & .218 \\
\hline 7 & $\begin{array}{c}3.11 \\
(1.17)\end{array}$ & $\begin{array}{r}1.14 \\
(21.9)\end{array}$ & $\begin{array}{r}.152 \\
(1.67)\end{array}$ & .889 & 1.84 & .180 \\
\hline 8 & $\begin{array}{r}.135 \\
(1.17)\end{array}$ & $\begin{array}{r}1.08 \\
(24.3)\end{array}$ & $\begin{array}{r}.088 \\
(1.13)\end{array}$ & .913 & 2.08 & .154 \\
\hline 9 & $\begin{array}{l}.422 \\
(.517)\end{array}$ & $\begin{array}{r}1.07 \\
(34.0)\end{array}$ & $\begin{array}{r}.130 \\
(2.34)\end{array}$ & .951 & 2.12 & .109 \\
\hline 10 (Largest) & $\begin{array}{c}-1.85 \\
(-2.28)\end{array}$ & $\begin{array}{r}1.02 \\
(32.7)\end{array}$ & $\begin{array}{c}.043 \\
(.781)\end{array}$ & .951 & 2.05 & .109 \\
\hline EVW & 0.0 & 1.00 & 0.00 & 1.00 & - & 0.00 \\
\hline EEW & $\begin{array}{c}3.55 \\
(1.88)\end{array}$ & $\begin{array}{r}1.18 \\
(16.2)\end{array}$ & $\begin{array}{c}-.007 \\
(-.056)\end{array}$ & .834 & 2.17 & .253 \\
\hline
\end{tabular}

Regressions of the excess return of size-sorted portfolios on the excess retum to the value-weighted CRSP portfolio, an intercept, and the excess return to a put option on the market index (NPUT). See the text for a fuller description of the NPUT. T-statistics (in parentheses) are computed using the Hansen-White heteroskedasticity-consistent standard errors.

\section{Acknowledgments}

We would like to thank Roy Henriksson and David Modest for generously providing the mutual fund return data used in this study. Helpful comments were received from Stephen Brown and Michael Gibbons. We would like to thank Helena Mullins, G. Sharathchandra, and Robert Uhlaner for research assistance.

\section{Appendix}

This appendix describes the assumptions behind the rotational procedure used in the text and derives the asymptotic distribution of the resulting beta and alpha estimates. We assume 


$$
\begin{aligned}
& \mathbf{m}=\mathbf{m}^{*}+\eta \\
& \mathbf{f}=E[\mathbf{f}]+\mathbf{m}^{*} \\
& r=\alpha+\beta \mathbf{f}+\boldsymbol{\epsilon}
\end{aligned}
$$

$\epsilon, \eta$ independent and i.i.d. through time

$$
E[\epsilon \mid \mathbf{f}]=0, E[\eta \mid \mathbf{f}]=0
$$

Let $F, \tilde{F}, \tilde{G}$, and $\hat{F}$ be defined as in the text. We treat $F$ and $G$ as nonrandom sequences of matrices as is standard in least squares theory. We make three standard assumptions of least squares theory:

$$
\begin{aligned}
& \lim _{T \rightarrow \infty}\left[\frac{1}{T} \tilde{F} \tilde{F}^{\prime}\right]^{-1}=\Lambda_{F}^{*} \\
& \operatorname{dim}_{T \rightarrow \infty} \frac{1}{\sqrt{T}} \iota^{\prime} \epsilon \sim N\left(0, \sigma_{\epsilon}\right), \text { where } \iota \text { denotes a } T \text {-vector of ones } \\
& \operatorname{dim}_{T \rightarrow \infty} \frac{1}{\sqrt{T}} \beta \tilde{F} \tilde{\eta}^{\prime} \sim N\left(0, \Sigma_{\beta F \eta}\right) .
\end{aligned}
$$

We first wish to show that an asset's betas with respect to the rotated factors $\hat{F}$ approach the betas with respect to the true factors $F$. Recall from the text that our beta estimator can be written as

$\hat{\beta}=\tilde{R} \hat{F}^{\prime}\left(\hat{F} \hat{F}^{\prime}\right)^{-1}=(\beta \tilde{F}+\tilde{\epsilon}) \tilde{G}^{\prime}\left(\tilde{G} \tilde{G}^{\prime}\right)^{-1} \tilde{G}(\tilde{F}+\tilde{\eta})^{\prime}\left((\tilde{F}+\tilde{\eta}) \tilde{G}^{\prime}\left(\tilde{G} \tilde{G}^{\prime}\right)^{-1} \tilde{G}(\tilde{F}+\tilde{\eta})^{\prime}\right)^{-1}$.

Using $\tilde{G}^{\prime}\left(\tilde{G} \tilde{G}^{\prime}\right)^{-1} \tilde{G}=\tilde{F}^{\prime}\left(\tilde{F} \tilde{F}^{\prime}\right)^{-1} \tilde{F}$ and combining terms, this becomes

$$
\begin{gathered}
\hat{\beta}=\left[\left(\beta \tilde{F} \tilde{F}^{\prime}+\epsilon \tilde{F}^{\prime}+\beta \tilde{F} \tilde{\eta}^{\prime}+\tilde{\epsilon} \tilde{F}^{\prime}\left(\tilde{F} \tilde{F}^{\prime}\right)^{-1} \tilde{F} \tilde{\eta}^{\prime}\right)\right. \\
\left.\cdot\left(\tilde{F} \tilde{F}^{\prime}+\eta \tilde{F}^{\prime}\left(\tilde{F} \tilde{F}^{\prime}\right)^{-1} \tilde{F} \eta^{\prime}+\eta \tilde{F}^{\prime}+\tilde{F} \eta^{\prime}\right)^{-1}\right]
\end{gathered}
$$

We have the following.

Theorem 1. Given equations (17)-(24), $\operatorname{plim}_{T \rightarrow \infty} \hat{\beta}=\beta$ and

$$
\operatorname{dim}_{T \rightarrow \infty} \sqrt{T}(\hat{\beta}-\beta) \sim N\left(O, \Lambda_{F}^{*} \Sigma_{\beta F \eta} \Lambda_{F}^{*}+\sigma_{\epsilon} \Lambda_{F}^{*}\right) .
$$


Proof. From equation (25) we have

$$
\begin{aligned}
\operatorname{dlim}_{T \rightarrow \infty} & \sqrt{T}(\hat{\beta}-\beta) \\
= & -\sqrt{T} \beta+\left(\sqrt{T} \beta\left(\frac{1}{T} \tilde{F} \tilde{F}^{\prime}\right)+\frac{1}{\sqrt{T}} \tilde{\epsilon} \tilde{F}^{\prime}+\frac{1}{\sqrt{T}} \beta \tilde{F} \tilde{\eta}^{\prime}+\left(\frac{1}{T}\right)^{3 / 2} \tilde{\epsilon} \tilde{F}^{\prime}\left(\frac{1}{T} \tilde{F} \tilde{F}^{\prime}\right)^{-1} \tilde{F} \tilde{\eta}\right) \\
& \cdot\left(\frac{1}{T} \tilde{F} \tilde{F}^{\prime}+\left(\frac{1}{T}\right)^{2} \tilde{\eta} \tilde{F}^{\prime}\left(\frac{1}{T} \tilde{F} \tilde{F}^{\prime}\right)^{-1} \tilde{F} \tilde{\eta}^{\prime}+\frac{1}{T} \tilde{\eta} \tilde{F}^{\prime}+\frac{1}{T} \tilde{F} \tilde{\eta}^{\prime}\right)^{-1}
\end{aligned}
$$

We have $\operatorname{plim}(1 / T)^{\gamma} \tilde{\epsilon} \tilde{F}^{\prime}=0$ and $\operatorname{plim}(1 / T)^{\gamma} \tilde{F} \tilde{\eta}^{\prime}=0$ for any $\gamma>1 / 2$. Applying this to equation (26) above gives

$$
\begin{aligned}
\operatorname{dlim}_{T \rightarrow \infty} \sqrt{T}(\hat{\beta}-\beta)= & -\sqrt{T} \beta+\left[\sqrt{T} \beta\left(\frac{1}{T} \tilde{F} \tilde{F}^{\prime}\right)+\frac{1}{\sqrt{T}} \tilde{\epsilon} \tilde{F}^{\prime}+\frac{1}{\sqrt{T}} \beta \tilde{F} \tilde{\eta}^{\prime}\right] \\
& \cdot\left[\underset{T \rightarrow \infty}{\operatorname{plim}}\left(\frac{1}{T} \tilde{F} \tilde{F}^{\prime}\right)^{-1}\right] .
\end{aligned}
$$

Since

$$
\underset{T \rightarrow \infty}{\operatorname{dlim}} A B=\underset{T \rightarrow \infty}{\operatorname{dijm}} A \cdot \underset{T \rightarrow \infty}{\operatorname{plim}} B
$$

for fixed-dimensional sequences of matrices $A$ and $B$, this gives

$\operatorname{dim}_{T \rightarrow \infty} \sqrt{T}(\hat{\beta}-\beta)=\operatorname{dlim}_{T \rightarrow \infty}\left(\frac{1}{\sqrt{T}} \tilde{\epsilon} \tilde{F}^{\prime}\left(\frac{1}{T} \tilde{F} \tilde{F}^{\prime}\right)^{-1}+\frac{1}{\sqrt{T}} \beta \tilde{F} \tilde{\eta}^{\prime}\left(\frac{1}{T} \tilde{F} \tilde{F}^{\prime}\right)^{-1}\right]$.

This is asymptotically a finite linear combination of multivariate normals and so is asymptotically multivariate normal. Note that it has zero mean. To find the asymptotic covariance matrix, we take the expectation of the outer product:

$$
\lim _{T \rightarrow \infty} E\left[T(\hat{\beta}-\beta)^{\prime}(\hat{\beta}-\beta)\right]=\Lambda_{F}^{*} \Sigma_{\beta F \eta} \Lambda_{F}^{*}+\sigma_{\epsilon} \Lambda_{F}^{*}
$$

Theorem 1 gives the variances of the beta estimates independent of the factor rotation. We can also derive a simpler variance formula that is conditional on the particular rotation. Define $\beta^{*}$ as the beta vector times the rotational error matrix $\hat{L}$ :

$$
\beta^{*}=\beta\left(\tilde{F} \hat{F}^{\prime}\left(\hat{F}^{\prime} \hat{F}\right)^{-1}\right)=\beta \hat{L} .
$$

From theorem 1 we can show

$$
\underset{T \rightarrow \infty}{\operatorname{plim}} \hat{L}=I_{k} .
$$


Now we give a result that is conditional on the particular realized value of $\hat{L}$ (or equivalently $\hat{F}$ ).

Theorem 2. Given equations (17)-(24), $\left[\left(\hat{\beta}-\beta^{*}\right) \mid \hat{F}\right] \sim N\left(O, \sigma_{\epsilon}\left(\hat{F} \hat{F}^{\prime}\right)^{-1}\right)$.

Proof. Using the definitions of $\hat{\beta}$ and $\beta^{*}$,

$$
\left(\hat{\beta}-\beta^{*}\right)=\left(\epsilon \hat{F}^{\prime}\left(\hat{F} \hat{F}^{\prime}\right)^{-1}\right),
$$

which is normally distributed conditional on $\hat{F}$. It has covariance matrix

$$
\begin{array}{r}
E\left[\left(\hat{F} \hat{F}^{\prime}\right)^{-1} \hat{F} \in \epsilon^{\prime} \hat{F}^{\prime}\left(\hat{F} \hat{F}^{\prime}\right)^{-1} \mid \hat{F}\right]=\left(\hat{F} \hat{F}^{\prime}\right)^{-1} \hat{F} \sigma_{\epsilon} I_{T} \hat{F}^{\prime}\left(\hat{F} \hat{F}^{\prime}\right)^{-1}=\sigma_{\epsilon}\left(\hat{F} \hat{F}^{\prime}\right)^{-1} . \\
\text { Q.E.D. }
\end{array}
$$

This theorem can easily be extended to the case where $\epsilon$ is not normal but $(1 / \sqrt{T}) \epsilon \hat{F}^{\prime}$ is asymptotically normal.

The distributions of our estimates of $\alpha$ and $\epsilon$ are the easiest to derive, since they do not depend on the rotation.

Theorem 3. Let $\hat{\alpha}$ and $\hat{\epsilon}$ be estimated by applying ordinary least squares to the true factors in $\mathbf{R}=\hat{\alpha}+\hat{\beta} F+\hat{\epsilon}$, and let $\hat{\alpha}^{\prime}$ and $\hat{\epsilon}^{\prime}$ be estimated from using the rotated factors in $\mathbf{R}=\hat{\alpha}^{\prime}+\hat{\beta}^{\prime} \hat{F}+\hat{\epsilon}^{\prime}$. Then $\hat{\alpha}^{\prime}=\hat{\alpha}$ and $\hat{\epsilon}^{\prime}=\hat{\epsilon}$.

Proof. The intercept and residual estimates in ordinary least squares are unaffected by a rotation of the independent variables. See Theil (1971, pp. 39-41).

\section{Notes}

1. Note that the expected value of $\mathbf{f}$ corresponds to the vector of factor risk premiums.

2. An earlier version of this article also included results using the equally weighted CRSP portfolio (see Connor and Korajczyk, 1988b).

3. By shock we mean the zero-mean innovation in the series.

4. In fact, these portfolios are not truly informationally passive. In forming them, we were motivated by our ex post knowledge of a size-based return premium for the CAPM during this sample period (see Lo and MacKinlay, 1990).

5. Lee and Rahman (1990) have found successful timing and selection ability on a sample of mutual funds using the timing measure of Pfleiderer and Bhattacharya (1983).

6. As shown by Grinblatt and Titman (1989), an investor with superior information and increasing absolute risk aversion might rationally choose to engage in perverse market timing. This seems to require extreme assumptions about investor risk aversion.

7. Glosten and Jagannathan (1988) argue that performance evaluation based on a simple options pattern such as this should be viewed as an approximation to the true performance value of a manager who trades a variety of options or optionlike securities. 


\section{References}

Breeden, Douglas, T., Gibbons, Michael R, and Litzenberger, Robert H., "Empirical Tests of the ConsumptionOriented CAPM," Journal of Finance, 44, 231-262 (1989).

Chang, Eric C., and Lewellen, Wilbur, G., "Market Timing and Mutual Fund Investment Performance," Journal of Business, 56, 57-72 (1984).

Chen, Nai-fu, Roll, Richard, and Ross, Stephen A., "Economic Forces and the Stock Market," Joumal of Business, 59, 383-403 (1986).

Connor, Gregory, and Korajczyk, Robert A., "Performance Measurement with the Arbitrage Pricing Theory: A New Framework for Analysis," Journal of Financial Economics, 15, 373-394 (1986).

Connor, Gregory, and Korajczyk, Robert A., "Risk and Return in an Equilibrium APT: Application of a New Test Methodology,” Journal of Financial Economics, 21, 255-289 (1988a).

Connor, Gregory, and Korajczyk, Robert A., "The Attributes, Behavior, and Performance of U.S. Mutual Funds," Working Paper $\$ 39$ o, Department of Finance, Northwestern University, March (1988b).

Connor, Gregory, and Uhlaner, Robert, "Cross-Sectional Regression Tests of Beta Pricing Models," Working Paper, School of Business Administration, University of California, Berkeley (1987).

Fama, Eugene F., and MacBeth, James D., "Risk, Return and Equilibrium: Empirical Tests," Journal of Political Economy, 81, 607-636 (1973).

Glosten, Lawrence R., and Jagannathan, Ravi, "A Contingent Claim Approach to Performance Evaluation," Working Paper \#54, Department of Finance, Northwestern University, August (1988).

Grinblatt, Mark, and Titman, Sheridan, "Portfolio Performance Evaluation: Old Issues and New Insights," Review of Financial Studies, 2, 393-421 (1989).

Henriksson, Roy D., "Market Timing and Mutual Fund Performance: An Empirical Investigation," Journal of Business, 57, 73-96 (1984).

Henriksson, Roy D., and Merton, Robert C., "On Market Timing and Investment Performance II: Statistical Procedures for Evaluating Forecasting Skills," Journal of Business, 54, 513-533 (1981).

Hsieh, David A., "A Heteroscedasticity-Consistent Covariance Matrix Estimator for Time Series Regressions," Journal of Econometrics, 22, 281-290 (1983).

Jagannathan, Ravi, and Korajczyk, Robert A., "Assessing the Market Timing Performance of Managed Portfolios," Journal of Business, 59, 217-235 (1986).

Jensen, Michael C., "The Performance of Mutual Funds in the Period 1945-1964," Journal of Finance, 23, 389-416 (1968).

Lee, Cheng-few, and Rahman, Shafigur, "Market Timing, Selectivity, and Mutual Fund Performance: An Empirical Investigation," Journal of Business, 63, 261-278 (1990).

Lehmann, Bruce N., and Modest, David M., "Mutual Fund Performance Evaluations: A Comparison of Benchmarks and Benchmark Comparisons," Journal of Finance, 42, 233-265 (1987).

Lehmann, Bruce N., and Modest, David M., "The Empirical Foundations of the Arbitrage Pricing Theory," Journal of Financial Economics, 21, 213-254 (1988).

Lo, Andrew W., and MacKinlay, A. Craig, "Data-Snooping Biases in Tests of Financial Asset Pricing Models," Review of Financial Studies. Forthcoming (1990).

Ketterer, Juan, “Asset Pricing with Differential Information,” Working Paper, Department of Finance, Northwestern University (1987).

McElroy, Marjorie B., and Burmeister, Edwin, "Arbitrage Pricing Theory as a Restricted Nonlinear Multivariate Regression Model," Journal of Business \& Economic Statistics, 6, 29-42 (1988).

Merton, Robert C. , "On Market Timing and Investment Performance I: An Equilibrium Theory of Value of Market Forecasts," Journal of Business, 54, 363-406 (1981).

Pfleiderer, Paul C., and Bhattacharya, Sudipto, "A Note on Performance Evaluation," Technical Report \#714, Graduate School of Business, Stanford University (1983).

Roll, Richard, "Ambiguity when Performance is Measured by the Security Market Line," Journal of Finance, 33, 1051-1069 (1978).

Ross, Stephen A., "The Arbitrage Theory of Capital Asset Prices," Joumal of Economic Theory, 13, $341-360$ (1976). Shanken, Jay, "Multivariate Proxies and Asset Pricing Relations: Living with Roll Critique," Journal of Financial Economics, 18, 91-110 (1987).

Theil, Henri, Principles of Econometrics, New York, Wiley, 1971.

Wei, K.C. John, "An Asset Pricing Theory Unifying the CAPM and APT," Journal of Finance, 43, 881-892 (1988).

White, Halbert, "A Heteroscedasticity-Consistent Covariance Matrix and a Direct Test of Heteroscedasticity," Econometrica, 48, 817-838 (1980). 